\title{
Determining when to recommend continent urinary diversion
}

\section{Scott M. Gilbert, MD, MS; James E. Montie, MD}

$\mathrm{F}$ or many bladder cancer patients diagnosed with muscle-invasive disease and in cases of high-risk progressive noninvasive disease, cystectomy is an effective treatment, offering diseasespecific survival of about $87 \%$. $^{1}$ Bladder cancer survivors, however, face a multitude of health-related consequences following cystectomy. These are mostly related to urinary diversion and reconstruction. While improvements in perioperative care have decreased the surgical morbidity following cystectomy, ${ }^{2}$ the complications and functional consequences associated with urinary diversion remain problematic. As a result, the functional and healthrelated quality of life issues following cystectomy are substantial for this group of cancer survivors.

The impact of urinary diversion has long been recognized as a major shortcoming of cystectomy and has prompted interest in limiting the adverse functional effects associated with surgical removal of the bladder. Several forms of continent urinary diversion have been developed and refined with the objective of decreasing the burdens associated with diversion. ${ }^{3,4}$ In addition, the options and recommended use of continent diversion have expanded during the past decade, and currently, proponents of continent diversion estimate that $80 \%$ of men and greater than $65 \%$ of women with invasive bladder cancer are candidates for orthotopic continent urinary diversion. ${ }^{5}$ Most cystectomy patients, however, do not receive continent reconstruction. ${ }^{6}$ Although the reasons are not entirely clear, significant baseline infirmity and comorbidity, technical complexity, risk of complications ${ }^{7}$ and uncertainty regarding a health-related quality of life benefit have likely limited widespread adoption of continent reconstruction.

Although the optimal type of urinary reconstruction has not been firmly established, ${ }^{7-9}$ continent diversion offers potential advantages through maintenance of anatomic voiding, approximation of normal functional voiding and preservation of preoperative body image. Previous work has shown that complications following this type of diversion are modifiable and that cancer control and survival are independent of the type of urinary diversion used. 3,10,11 Experienced groups have reported improvement in short- and long-term complications ${ }^{3}$ as well as satisfactory urinary continence in up to $95 \%$ of patients following continent urinary diversion. ${ }^{12}$ While these results are likely not generalizable and may overestimate the health-related quality of life benefit of continent orthotopic urinary diversion, they do underscore the potential benefit of continent diversion when used in the right setting.

Still, comparisons of functional outcomes and health-related quality of life in bladder cancer survivors managed with continent and incontinent urinary diversion have been difficult to interpret. To date, methodology has been limited ${ }^{7-9,13}$ and results have been mixed. ${ }^{14-20}$ While general health-related quality of life appears to be similar in both, ${ }^{21}$ specific issues concerning body image, problematic urine leakage and decreased sexual functioning have been inconsistent, although more commonly reported following ileal conduit diversion..$^{22}$ Even so, each type of urinary diversion is associated with a different set of well-described treatment-related effects. In those managed with ileal conduit, concern centres
The purpose of the Point / Counterpoint section is to encourage vigorous and informed discussion on controversial issues in urology through the presentation of diverse opinions. We aim for a dispassionate discussion of controversies, recognizing that strong passions may exist in support of some positions. 
around the urinary stoma, external urinary appliance and the consequent negative impact on body image. Other factors that appear to be of particular concern to this group include urinary leakage, skin irritation and excoriation, sexual dysfunction and gastrointestinal problems. ${ }^{23-29}$ Urinary incontinence, particularly nighttime incontinence, appears to be the principal issue in patients managed with continent orthotopic urinary diversion. Catheterization poses its own set of concerns related to frequency, discomfort and inconvenience following continent nonorthotopic urinary diversion and in men and women who catheterize following orthotopic diversion because of urinary retention. ${ }^{8}$

The impact of suboptimal outcomes may affect quality of life beyond the obvious functional impairments documented to date. Several prior studies have found that patients treated with orthotopic continent diversion are more likely to travel, to engage in leisure activities and to suffer fewer social deficits than those managed with incontinent diversions..$^{19,22,30-32}$ Others have found that urinary leakage is a greater concern among patients treated with ileal conduit, compared with continent diversion, ${ }^{14,33,34}$ which may contribute to less social behaviour.

In truth, the negative consequences of incontinent diversion and positive functional outcomes following continent diversion have likely been exaggerated in opposite directions. As noted previously, direct comparisons of incontinent and continent urinary diversion are challenging for a variety of reasons. Issues related to the advanced age of the average cystectomy patient, varying levels of infirmity and, in some cases, relatively low baseline functioning undoubtedly contribute to detected differences in functional outcomes between urinary diversion groups. Few studies, however, have accounted for these important differences, making much of what has been reported susceptible to confounding by indication. This circumstance underscores a principal challenge in this area of outcomes research; continent urinary diversion patients tend to be more active and healthier than their older, more infirm ileal conduit counterparts, and comparison of functional and health-related quality of life outcomes may therefore not be balanced.

A second limitation in urinary diversion comparisons relates to the lack of disease-specific outcome measures. Most previous research has relied on general measures, which are typically unresponsive to the most clinically relevant differences, or have used informally developed questions, in which case the ability to reliably detect true differences is uncertain. Unfortunately, few reliable, responsive and valid health-related quality of life instruments are currently available for bladder cancer, and those that have been developed are in the early stages of validation and disseminated use. . $^{8,35-37}$ Consequently, health-related quality of life assessment in the area of urinary diversion has been incomplete to date, and as a discipline, we are just now embarking on reliable measurement.

Undoubtedly, functional outcomes, healthrelated quality of life and the survivorship experience can be improved following cystectomy and urinary diversion. Determining the extent of the problems associated with various types of urinary diversion will be an essential component in this effort. In the case of orthotopic continent urinary diversion, surgeons have underestimated the prevalence of urinary incontinence, and patientreported problems with urinary leakage and lack of control are apparent in greater than $50 \%$ of cases. ${ }^{37}$ Importantly, while urinary function is impaired following continent diversion, patients do not appear to be significantly bothered, ${ }^{37}$ suggesting that adaptation to functional impairments is also common. It is quite possible that factors such as patient values, expectations and preference for maintaining anatomic urinary function (voiding per urethra) in exchange for some impairment of normal voiding function (full urinary control) influence recovery and health-related quality of life following urinary diversion. For some patients, particularly those who are younger, more active and motivated to avoid an external urinary appliance and maintain anatomic voiding, continent diversion is likely the right choice. For others, incontinent diversion may be preferable.

While all surgeons involved in treating bladder cancer strive to limit the adverse impact of cystectomy, we can still do better. Tailoring the approach to urinary diversion is appealing because so much of how a patient recovers and adapts following surgery is mediated by their expectations and values. The marginal patient - the cases in which functional detriments are further exacerbated by expectations that are unmet by postdiversion outcome - is where major improvement can be achieved. Understanding the determinants of optimal 
care - knowing in which cases, for which patient and in which settings to recommend continent diversion - is a key element in this process.

From the Division of Urologic Oncology, Department of Urology, University of Michigan, Ann Arbor, Mich.

The positions provided in the Point/Counterpoint series are presented as general information and do not necessarily reflect the personal opinions of the authors.

This article has been peer reviewed.

Competing interests: None declared.

\section{References}

1. Stein JP, Lieskovsky G, Cote R, et al. Radical cystectomy in the treatment of invasive bladder cancer: Long-term results in 1054 patients. J Clin Oncol 2001;19:666-75.

2. Taub DA, Dunn RL, Miller DC, et al. Discharge practice patterns following cystectomy for bladder cancer: evidence for the shiffing of the burden of care. I Urol 2006;176:2612-7.

3. Madersbacher S, Studer UE. Contemporary cystectomy and urinary diversion. World J Urol 2002;20:151-7.

4. Hautmann RE, Volkmer BG, Schumacher MC, et al. Long-term results of standard procedures in urology: the ileal neobladder. World I Urol 2006;24:305-14.

5. Hautmann RE. Which patients with transitional cell carcinoma of the baldder or prostatic urethra are candidates for an orthotopic neobladder? Curr Urol Rep 2000;1:173-9.

6. Gore JL, Saigal CS, Hanley JM, et al. Urologic disease in America project: variations in reconstruction after radical cystectomy. Cancer 2006;107:729-37.

7. Gerharz EW, Mansson A, Hunt S, et al. Quality of life after cystectomy and urinary diversion: an evidence-based analysis. J Urol 2005;174:1729-36.

8. Botteman MF, Pashos CL, Hauser RS, et al. Quality of life aspects of bladder cancer: a review of the literature. Qual Life Res 2003;12:675-88.

9. Porter MP, Penson DF. Health related quality of life after radical cystectomy and urinary diversion for bladder cancer: a systematic review and critical analysis of the literature. J Urol 2005;173:1318-22.

10. Clark PE. Urinary diversion after radical cystectomy. Curr Treat Options Oncol 2002;3:389402

11. Krupski T, Theodorescu D. Orthotopic neobladder following cystectomy: indications, management, and outcomes. J Wound Ostomy Continence Nurs 2001;28:37-46.

12. Hautmann RE, De Petriconi R, Gottfried HW, et al. The ileal neobladder: complications and functional results in 363 patients after 11 years of followup. J Urol 1999;161:422-8

13. Nabi G, Yong SM, Ong E, et al. Is orthotopic bladder replacement the new gold standard? Evidence from a systematic review. J Urol 2005;174:21-8.

14. Bjerre BD, Johansen C, Steven K. Helath-related quality of life after cystectomy: bladder substitution compared with ileal conduit diversion. A questionnaire survey. Br J Urol 1995;75:200-5.

15. Bierre BD, Johansen C, Steven K. Sexological problems after cystectomy: bladder substitution compared to ileal conduit diversion. A questionnaire survey of male patients. Scand I Urol Nephrol 1998;32:187.

16. Fujisawa M, Isotani $S$, Gototh $A$, et al. Health-related quality of life with orthotopic neobladder versus ileal conduit according to SF-36 survey. Urology 2000;55:862-5.

17. Hobisch A, Tosun K, Kinzl I, et al. Quality of life after cystectomy and orthotopic neobladder versus ileal conduit urinary diversion. World J Urol 2000;18:338-44.
18. Hara I, Miyake H, Hara S, et al. Health-related quality of life after radical cystectomy for bladder cancer: a comparison of ileal conduit and orthotopic bladder replacement. BJU Int 2002:89:10-3.

19. Dutta SC, Chang SS, Coffey CS, et al. Health related quality of life assessment after radical cystectomy: comparison of ileal conduit with continent orthotopic neobladder. J Urol 2002;168:164-7.

20. Protogerou V, Moschou M, Antoniou N, et al. Modified S-pouch neobladder vs ileal conduit and a matched controlled population: a quality of life survey. BJU Int 2004;94: 350-4.

21. Hardt J, Filipas D, Hohenfellner R, et al. Quality of life in patients with bladder carcinoma affer cystectomy: first results of a prospective study. Qual Life Res 2000;9:1-12.

22. Okada Y, Oishi K, Schichiri Y, et al. Quality of life survey of urinary diversion patients: comparison of continent urinary diversion versus ileal conduit. Int J Urol 1997;4:26-41.

23. Jones MA, Breckman B, Hendry WK. Life with an ileal conduit: results of questionnaire surveys of patients with urological surgeons. Br J Urol 1980;52:21-5.

24. Fossa SD, Reitan JB, Ous $S$, et al. Life with an ileal conduit in cystectomized bladder cancer patients: expectations and experiences. Scand J Urol Nephrol 1987;21:97.

25. Mommsen S, Jakobsen A, Sell A. Quality of life in patients with advanced bladder cancer. A randomized study comparing cystectomy and irradiation - the Danish Bladder Cancer Study Group (DAVECA protocol 8201). Scand J Urol Nephrol Suppl 1989;125:115.

26. Chadwick DJ, Stower MJ. Life with urostomy. Br J Urol 1990;65:189-91.

27. Nordstrom GM, Nyman CR. Male and female sexual function and activity following ileal conduit urinary diversion. Br J Urol 1992; 70:33-9.

28. Nordstrom G, Nyman CR, Theorell T. Psychosocial adjustment and general state of health in patients with ileal conduit urinary diversion. Scand J Urol Nephrol 1992;26:139-47.

29. Henningsohn L, Wijkstrom H, Dickman PW, et al. Distressful symptoms after radical cystectomy with urinary diversion for urinary bladder cancer: a Swedish populationbased study. Eur Urol 2001;40:151-62.

30. Hobisch A, Tosun K, Kinzl J, et al. Life after radical cystectomy and orthotopic neobladder versus ileal conduit urinary diversion. Semin Urol Oncol 2001;19:18-23.

31. Kitamura H, Miyao N, Yanase M, et al. Quality of life in patients having ileal conduit, continent reservoir or orthotopic neobladder after cystectomy for bladder carcinoma. Int J Urol 1999;6:393-9.

32. Hart S, Skinner EC, Meyerowitz BE, et al. Quality of life after radical cystectomy for bladder cancer in patients with an ileal conduit, cutaneous or urethral Kock pouch. J Urol 1999;162:77-81.

33. Conde Redondo C, Estebanez Zarranz J, Rodriguez Tovez A, et al. [Quality of life in patients treated with orthotopic bladder substitution versus cutaneous ileostomy]. Actas Urol Esp 2001;25:435-44.

34. Mansson A, Johnson G, Mansson W. Quality of life after cystectomy: comparison between patients with conduit and those with continent caecal reservoir urinary diversion. $\mathrm{Br} J$ Urol 1988; 62:240-5

35. Porter MP, Wei JT, Penson DF. Quality of life issues in bladder cancer patients following cystectomy and urinary diversion. Urol Clin North Am 2005;32:207-16.

36. Cookson MS, Dutta SC, Chang SS, et al. Health related quality of life in patients treated with radical cystectomy and urinary diversion for urothelial carcinoma of the bladder: development and validation of a new disease specific questionnaire. J Urol 2003:170:1926-30

37. Gilbert SM, Wood DP, Dunn RL, et al. Measuging healthrelatated quality of life outcomes in bladder cancer patients using the bladder cancer index (BCl). Cancer 2007;109:1756-62.

Correspondence: Dr. Scott M. Gilbert, Department of Urology, University of Michigan 3875 Taubman Center, 1500 East Medical Center Dr., Ann Arbor MI 48109; scotgilb@med.umich.edu 